\title{
A Study on the Traditional Chinese Traditional Architectural Form of Mythological Tradition
}

\author{
XIONG Cheng-xia, ZHANG Ai-jia \\ University of Shanghai for Science and Technology, Shanghai 200093
}

\begin{abstract}
Objective Through the metaphorical archetypal spirit and mythological semantics of Chinese character structure, this paper explores the metaphorical mythological gene and the moral order of the Chinese character structure, geographical thinking and aesthetic orientation of the mythological prototypes derived from the Chinese characters. Method The cultural archetypes and the theories of big and small traditions are adopted to sort out the mythological beliefs in the former architectural forms of the big traditions and the ethical narrative system carried by the buildings in the small cultural traditional societies. In the architectural archetypes dominated by big and small cultural traditions, the thinking of "archetypes and ethics" is found to be a homologous gene, which confirms the universal significance of the spirit of Chinese Confucian ethics to the power of Chinese civilization flowing and inheriting and human morality. Conclusion The structure of Chinese characters has the function of "recording” and "interpreting", and the mythological thinking of architectural form materials, understands the ultimate transformation of cultural archetypes in creation, and guides the value of the traditional architectural design of "bringing out goodness and symbiosis" in the contemporary era. To relieve the material pursuit of spiritual enjoyment at that moment, to promote cultural heritage and the role of social treatment, to build cultural identity and the spiritual transcendence of the existence value of space ethics and the overall social and cultural identity.
\end{abstract}

Keywords: architectural mythology, Chinese character structure, original thinking, social ethics, the order of human relations

Through the metaphorical archetypal spirit and mythological semantics of Chinese character structure, this paper explores the metaphorical mythological gene and the moral order of the Chinese character structure, geographical thinking and aesthetic orientation of the mythological prototypes derived from the Chinese characters. The cultural archetypes and the theories of big and small traditions are adopted to sort out the mythological beliefs in the former architectural forms of the big traditions and the ethical narrative system carried by the buildings in the small cultural traditional societies. In the architectural archetypes dominated by big and small cultural traditions, the thinking of "archetypes and ethics" is found to be a homologous gene, which confirms the universal significance of the spirit of Chinese Confucian ethics to the power of Chinese civilization flowing and inheriting and human morality. The structure of Chinese characters has the function of "recording" and "interpreting”, and the mythological thinking of architectural form materials, understands the ultimate transformation of cultural archetypes in creation, and guides the value of the traditional architectural

Fund projects: Project of National Natural Science Youth Foundation of China (5160081221).

Correspondent Author: XIONG Cheng-xia, Room 2803, No. 18, Lane 303, Caoyang Road, Putuo Area,Shanghai, China 
design of "bringing out goodness and symbiosis" in the contemporary era. To relieve the material pursuit of spiritual enjoyment at that moment, to promote cultural heritage and the role of social treatment, to build cultural identity and the spiritual transcendence of the existence value of space ethics and the overall social and cultural identity.

China has four distinct seasons and diverse geographical and topographic features, and its ancestors had already mastered the skills of farming and settlement and their survival experience ten thousand years ago. Get rough and brief experience of creation in the withered and glory of plant, animal reproduction and farming replacement, cultivate the myth belief of "metabolism" and "symbiosis" in hemp, beans, wheat, millet and millet. These beliefs and experiences eventually became the gene for the creation of Chinese characters and preserved the primitive myths of the ancestors.

Chinese characters construct the cultural memory of meaning type, compose the life tropism of "seeking truth from this" and "neutralization of order", correspond to "the difference between the family and the state" and "the objectification of personality", reveal the spiritual path of the "ethical level" and "the respect and inferiority of heaven and earth" in the temple clan.

For a long time, the research on the relationship between Chinese characters and their spatial orientation and ethical symbols has been mostly focused on the text semantic state of linguistics, anthropology and philosophical psychology, while the research on the relationship between Chinese characters and spatial narrative and architectural ethics has had little impact. The contemporary national cultural renaissance needs to concentrate the strength of various fields from a strategic position. Mr. Ye Shuxian regards the appearance of characters as the dividing line of cultural archetypes, takes the tradition which precedes and is outside the characters as the big tradition, (Ye 2015:22) and takes the writing tradition as the minor tradition, and sorts out the new research paradigm of Chinese cultural studies. Peng Zhaorong interpreted the relationship between ancient Chinese characters and mine farming in terms of location, which eventually led to the urban model of "King governing the world" (Peng 2016:55). Zhang Weijia explored the form of cultural psychology from the aspects of architectural space etiquette and the national psychological structure of Chinese characters, and dissected the prototype of space etiquette according to the meaning of ancient books and records (Zhang 1994:107). Chen Wen-min put forward that ancient images and symbols such as ancient rock paintings, utensils, oracle-bone inscriptions, shape, sound and meaning system of oracle-bone inscriptions should be used to make up for the defects of historical materials to interpret Chinese mythology history (Chen 2016:71). Han Wei deliberated the scientific and technological information in ancient architecture from the structure of Chinese characters, and analyzed the connotation of social collective consciousness in Chinese characters (Han 2011:241). By looking for the metaphors of the prehistoric space planning principles in the locative words, Wang sa and others think that the locative words are metaphors of the Chinese traditional spatial diagrams and ethical order (Wang 2014:75). Zhang Jun thinks that Chinese characters are the intuitive thinking of the Han nationality, the abstract thinking of picture-text movement, the image thinking of creating artistic conception, and the national cultural psychology of object image, mental image and image formed by ancient Chinese characters (Zhang J, and Xu L2016: 73). These studies provide a broad perspective for the exploration of "cultural symbols, spatial values and psychological awareness" of the multi-in-one thinking.

As we all know, the form of natural resources has a direct impact on the early culture of a nation and the archetypal thinking of production and habitation. At the same time, thinking in turn dominates people's creation of the environment and spiritual culture. 
It is not accidental for the ancestors to take "Chinese characters" as the cultural carrier to narrate the relationship between architecture and life. The architectural space provides the guarantee for the survival of life, and the genetic archetypes created by architecture are the mythological meanings handed down in the prehistoric and small traditions of Chinese civilization. Chinese characters act as an intermediary and record of the relationship between man and the universe, and between man and the order of ethics. Exploring the architectural gene significance of Chinese character association lies in finding the Chinese ethical belief and material symbol in metaphor.

\section{The Mythological Intention of Archetypal Thinking and Chinese Character Form}

Gu Jie-gang once said that history is the record of human activities. Without the land and the people who live on it, history cannot be made ( Gu 2015). Land is the lifeblood of farming culture, and Chinese civilization benefits from "yellow land" and "black land". Cultural tradition of "Tianxuan Rehmannia" is intended to do so. The color of the sky is deep and deep, the water roars from the west with silt and becomes the color of earth. Life on the land is inseparable from the water and the sun, metaphysics and Huang complete the replacement of a life order. The myth of water control spread all over the world, the control of flood is related to the strength and weakness of the nation, the Chinese civilization embodies its ethical thinking because of Gun and Yu. In the Old Testament, God blocked the original sin of man with floods in Genesis. According to the Chinese Book of Mountains and Seas, "the flood was monstrous, and Gun drowned the flood.” "Mencius Teng Wen Gong” records: "when the time to forgive, the world is still not flat. The flood flows crosswise and overflows in the world; the water is retrograde and overflows in China. The sacred book of the Mayan civilization, the Bobowu Sutra, also records that the gods punished humans with floods. Sumerian mythology, the God of the Wind and the King of the Gods were also prepared to use the flood to wipe out the human race. So why did the early mythology describe the concept of "water"? Why in the legend all take "the boat" as the space intermediary? Why human beings and gods can not get along harmoniously, tracing the genetic code of Chinese characters will set up the structural paradigm of culture-sized tradition.

In modern society, the power of tsunamis and rivers and lakes floods is still amazing.

Therefore, the beginning and the process of the whole human history are mainly embodied in the myth of "flood". To think perspectively, the prehistoric man faced the flood, and no rescue facilities such as stormboats, the only possibility was to "build" dikes, dams, high platforms, and city walls. According to the literature, Gun was the first man to build a city. "Gun managed water by building embankments." The dykes of Gun were all around towns and villages, like later walls” (Guo 2014). Flood management as a matter of great importance, based on the most readily available materials and processing techniques in the natural world, is the conquest skill expressed by prehistoric men in the form of 'brickwork and construction', which has been turned to oral and mythological records as experience. "Gun as the City of Gun" in "the Book of the World". Yu as Palace "er Ya Shi Wen.” The emperor cited the book "Yao made Yu Zuogong”. "Wu Yue Chun Qiu” said: "Yao was flooded, the people flooding, Sui, high and home." Yao hired forsaken, so that parishioners living in the mountains, the creation of a district. "Wu Yue Chun Qiu" also records: "Yao listened to the words of the four mountains, with Gun Xiushui, Gun said: the emperor suffered a natural disaster, Jue Li Bukang, is to build a city to build Guo, that Guguo. "the repeated records in the literature show that controlling water is like treating people, and their intention of life is also reflected in the structure of Chinese characters. There are more than 1200 Chinese characters formed by three points of water. Thus it can be seen that the consciousness of evading 
and reforming floods has inspired” building "and” building “. Just as the Gothic church towered into the clouds, the fire towering minarets were built in response to the doomsday fears of the Middle Ages, reflecting the renunciation of worldly religious ideas. According to Jung, "language is essentially a system of symbols or symbols, which represents the reaction of a real event or a real event in the human mind" (Carl, and Sun 2011). In prehistoric times, people chose effective natural materials to create space, accompanied by the desire to "record" at the same time as they began to build, and the behaviors of controlling water inspired the pictographic expression of the text structure and the narrative of the language. This is the direct transfer of "dexterity to the mind". The prehistoric man collected the concrete appearance in the nature, summarized and reduced the house, the plant, the animal as well as their combination. Thus the writing were produced. The sun, the moon, the yin and yang, the sky and the sun, the earth and the sky, the human being circulates constantly in space, not in the living space, but in the public space or the boat-walking space. Although the prehistoric man melts into the natural environment, he also survives in the "space". The space under the sky is the source code of his thinking, the heaven and the earth are all knowledge systems, and it is by no means accidental to create the space expression in the consciousness. Just as Mr. Li Yun-li said, "because houses are concrete objects, when writing was created, the writing itself recorded the situation of the 'building', including its shape and contents. Therefore, it can be said that the Chinese text itself wrote the first chapter of the history of the development of Chinese architecture” (Li 2014).

Under the guidance of the experience of prehistoric collective fear of water, water control, water sacrifice , "building a city for governance" gradually rose to the state level. The architecture also turns to interpret the multi-dimensional contextual function of "social ethics" bearing the "ethical ideal". Human behavior is released and integrated into urban planning and architecture, and the ritual function of architecture is reflected in the structure of Chinese characters. The Ming Hall, surrounded by the founder structure, symbolizes the magnanimity of the state of the patriarchal temples, and expresses the social hierarchy of "solid gold soup" and "order of order" in the symmetrical space of separation of the central axis. The unified thought of "conquest" is melted in the sacrificial environment created by the decoration of architectural utensils. As Mr. Li Zehou said: "Human beings have language, but not only to exchange information, but also in the storage and use of the life experience of manufacturing tools.” It constitutes the original meaning of human language (Li 2015). Each chapter of "Zhou Li" starts with "only Wang Jianguo, the right position of the defense, the country and the country, the separation of officials and posts, and the policy of serving the people”. What it opens is the affirmation of space as the general plan of running the country. In the construction of folk houses, the structure of "clear primary and secondary order and well natural order" is obeyed. This kind of thinking is reflected by the structure of Chinese characters with big mouth frame. There are 759 characters with big mouth frame in Chinese dictionary. The "mouth" box echoes the symmetrical and rigorous structure and the spatial consciousness of "governing", describes the inner wishes of people facing the mysterious and powerful natural world, and stimulates the exaggeration and metaphor of the normal things. Thus created a mythological context, and ultimately converted into a variety of conditions between clans and tribes between the supernatural acts of God.

\section{Progressive Ethical Evolvement genes in Chinese Character Symbols}

"Myth is a strange system. It is constructed from a semiotic chain that predates it: it is a semiotic system of the second order. That is a symbol in the first system, a signifier in the second system. As long as they are 
subject to myth, no matter how different they may be at first, they are reduced to a purely referential function (Butt. R 1999). "At the same time, the prehistoric Chinese people unconsciously used the function of progressive evolution of mythology. Many of the structures of Chinese characters are complex characters, and independent characters are added to express the material characteristics, thus raising the single character to a compound signifier function. Such as the construction of jade space "Qionglou Yuyu”, "Diaolan Jade”, “Jinyu Man Tang” are built with jade rich and immortals of the house. Legend, "Yin Qi, the mother said Jian Di, there is the daughter of the Ming family." "there are nine layers of Yao Terrace built by Shi, Li Sao of qu Yuan, Yan Jian of Wang Yao Tai, the lost daughter of Zhai", and Records of History. Yin this period "three people walk bath, see Xuan bird fall its egg, Jane Di take swallow of, health contract. Jane Di lives on the Yao terrace, which is also a beautiful jade terrace, and it is up to nine storeys high. Wang Jia of the Jin Dynasty wrote, "there are twelve Yao terraces, each with thousands of steps, and all the five colored jade are the base of the terrace in the Kunlun Mountains." "this reflects the merchant's fairy saint gene of the ancestor . The ancients to "nine” for respect, "Lao Tzu”: "Nine layers of Taiwan, from the tired soil.

In ancient times, the emperor was honored for the ninth five-year plan, and the expression of the nine-storey Yao terrace embodied the tribute of the merchants to their ancestors. The word "Wang" is accompanied by jade, so all the materials with virtue are related to the word "Wang". This shows that although Chinese characters are generated by a symbol, they can eventually be linked to a specific person and space, forming a sacred and pluralistic meaning.

The signifier of Chinese characters, which even traces back to the great cultural tradition, is the "creative imitation (Aristotle)" in "observing objects and taking images", which even traces back to the material materials that chose the living form and constructed the living scene because of the geographical appearance and original species in the former generation of Chinese characters in the "Yi Jing" (the Book of changes). The Chinese characters beside the word "water, earth, stone and wood" record the scientific and technological level of the prehistoric man's selection of materials and configurations. "Mencius Teng Wen Gong Xia": "when Yao, the water retrograde, excessive in China, the snake and dragon home, the people have no fixed."

The lower is the nest, the upper is the camp. "( Philosophers integration 1954)Mencius Justice" records two kinds of dwelling structures, “cave dwelling” and "nesting”. The Book of changes said,'in ancient times, caves lived in wild places. "the word" wild "oracle bone inscriptions around the wood, the middle for the earth, as shown in figure 1. (Soil, cultivated land)At this time, the character making genes show that the living environment of human beings is composed of wood and soil. The "Jian-mu" myth recorded in Shan Hai Jing also expresses people's reverence for trees, which is the necessary material for survival, and thus leads to the social holiness in the interpretation of mythology. The existence of the earth character in the word "wild" is further clarified by the inscription on gold $£^{+}+$the and also indicates the processing ability and scientific and technological ability of the land. The technological ability is visible in the At this time, the word “野” added with word “予” $\boldsymbol{Q}$, to expresses conscious farming critters and road manage. Obviously, the technology is lifted to the "planning" level of plough and forest. But the left of the seal character电 is a definite and conscious countryside .Omitting “林” $\mathbf{W} \boldsymbol{W}$ and “田” further enhanced the order status of “井田” measure. Carl Jung also mentioned in archetypal and Collective consciousness: "interpretation makes use of certain linguistic sources derived from primitive images." No 
matter where we approach this issue, we will find ourselves confronted with the history of language, images and themes that directly trace back to the original magical world. "(Carl Gustav Jung, and Sun Mingli 2011) this is why a large number of partial meanings in Chinese characters are not only to express the material structure but also to record the technical structure. When words are combined into words, the semantics will be further increased according to the scene and purpose. There are 1413 characters for "wood" in Kangxi Dictionary, of which more than 400 are related to architecture (Zhao 2006). From the myth of "building wood" to the integration of wood into life, the Chinese people have already established the life attitude of "entrusting the body to the Arbor". In addition to "wood", there are 463 "earth" characters, 327 "stone" characters, 365 "bamboo" prefixes and 243 golden characters in Chinese characters. These "wood”, "earth”, "stone”, "bamboo" and "gold" are not only materials, but also constitute "Taiwan", "pavilions", "city", "Guo" and other meaningful modeling space, both reflect the continuation of human life; It also sketches out the psychological code archetypes of "love for wood, land, water, and metallurgy" in Cathay.

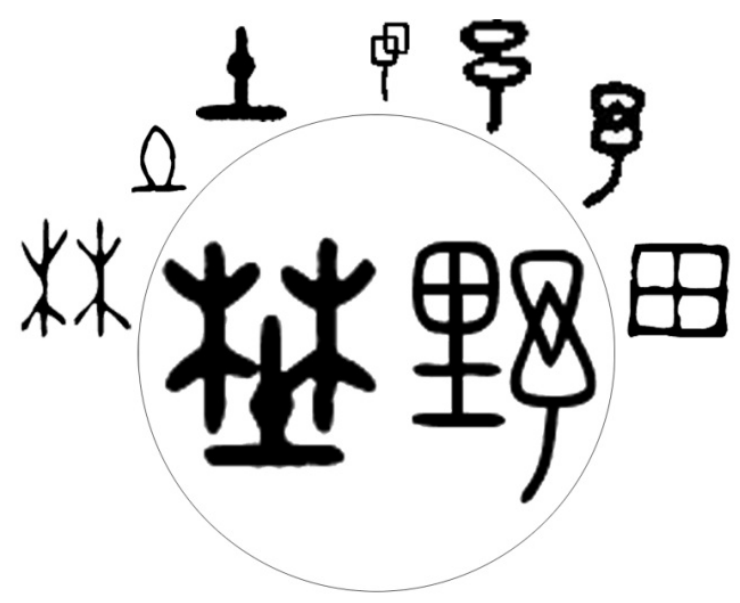

Figure 1. Structural cipher of Chinese characters.

Chinese characters also try to reflect the ethical progression of the structure in many ways. The original meaning of the word "Zu" in architecture is that materials are built by people to form a space body, such as "plate build", which splits two planks into a space. In the middle rammed earth for the wall, "the Book of songs Da Ya Mian": "its rope is straight, shrinks in order to carry, makes the temple wing, the rescue, the death of a prince, builds the dengdeng, cuts the Feng repeatedly.” A hundred blockades are all good, but a drum is victorious. "the craftsman can make the building straight and impartial, and plywood fill the earth wall, without the need for large-scale manpower, two people can work together, the general civil master and apprentice to build, so as to enhance the ethics of teachers in the practice of technology. Other architectural structures also produce ethical relations in cooperation. The "wooden bone and clay walls" express the harmonious ethical relations between craftsmen when they are being built with symmetrical structures, and also become the structural codes of Chinese characters. Therefore, Chinese characters in the pattern of advocating symmetry and balance, although the structure is not completely symmetrical, but strive to stroke density and symmetry. The Liangzhu culture discovered by archaeology had already had the mature edition to build the technique to deal with the Jiangnan swamp landform before 5000 years ago, but in the Hemudu culture near Liangzhu, it even popularized the tenon structure, embodying the farming life of "sinking the well and drinking, plowing the fields and feeding”. Here, "chisel” and "ploughing" are not only the expression of survival in response to the 
transformation of the natural environment, but also the reappearance of the technical structure and ethical wisdom of the ancestors.

The Chinese proverb also stores many ancient architectural information, such as step down, "can not be on the table," to enter the house, "because of the foundation of the building caused by the level of respect and inferiority. Due to the south-facing yang of the Chinese climate, the architecture adopts the layout of "sitting north facing south.” losing north "and" chasing after the north "and" opening the skylight to speak plainly "express the metaphor of light and failure caused by the orientation of the building. Du Fu's "Zhumen wine and meat smelly", "Chaimen", "Houmen deep as the sea" is the building and the status of the occupants linked together. "disintegration”, tile and tile linked together, over the years to uncover tile repair, remove obstruction and obstacles, and then extended to solve. Written records of people’s daily behavior and ethics.

\section{III.The Geo-Mythology of Chinese Character form and Traditional Architecture}

The Chinese geographical plane figure is just like the fabled "golden black" bird, the central plump, the northwest northeast extending beyond the boundary represent the communication, the southwest southeast Linhai presents the plump and mellow terrain. The geographical plane implies symmetry and balance, which coincides with the five directions of the Central Plains, and also shows the spatial geographical genes in the Chinese mythology. It is the cognition of the geographical environment that determines the success or failure of the farming civilization. the warring States Chu bamboo slips "Rong Cheng" 17th to 34 Jane of Shanghai Museum, recorded Dayu Tushan League: "Yu Li Wufang Hao flag, to distinguish between its left and right, think of the people without confusion. The eastern flag to the day, the western flag to the month, the southern flag to snake, the national flag to bear, the northern flag to birds. "Zuo Zhuan Xianggong four years": "Mangman Yuji, as Kyushu, by Kai Nine Road. "the Classic of Mountains and Seas and Sea": "the emperor ordered Yu Zou to lay the soil to set Jiuzhou." "Shiji Xia Benji" also recorded Dayu "trekking mountain surface wood, Dingshan Dachuan”, "left yardstick, right rules, set 04:00 to open Kyushu, Tongjiudaodao, broken nine Ze, degree nine mountains." All the "Kyushu" show that the Chinese people control the space, because the mythical thinking and the material narrative are synchronous, thus constructing the creation practice between the Chinese square and the circle, "the expression system and the cognitive thinking are each other inside and outside.” As the knowledge and skills of urban construction, the first is the application and practice of cognitive value. The Chinese culture has the special coordination with the city construction in the way of thinking, among which "square” is an important principle” (Peng ,and Zhou 2015).

"Yugong", "Yugong Jiuzhou mountains and rivers map" can also be seen in the Southern Song Dynasty Chunxi twelve years (1185) engraved ink printing. The plan shows the square layout, using solid lines to mark the Kyushu orientation. The dotted line shows the distribution of the "north-south western regions" and "three four columns" mountains and rivers, as shown in figure 2. In the map of the world drawn in the Qing Dynasty, we can still see the Chinese people's deep-rooted ideal structure of balanced symmetry on all sides of the "heaven, circle, and earth". This kind of thinking not only creates words but also reflects the homology of composition and aesthetic thinking in the history of fine arts. "the direction of East, West and North and South is connected with certain color, wind and myth activities through mysterious mutual infiltration;” And the latter is connected to rivers or sacred forests, and so on and so forth to infinity. "(Bruhl 1981)there is no doubt that the beauty of Chinese creation and the cultivation of mythology are closely related to the spatial geography of China. 


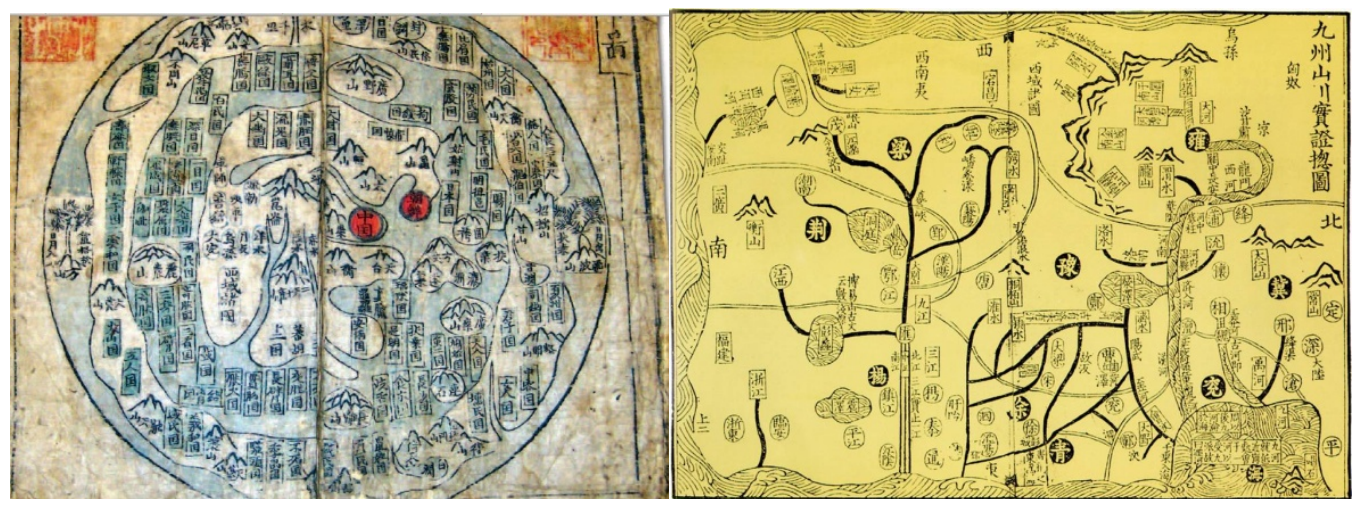

Figure 2. Mountains and rivers map of Jiuzhou in Yugong.

Map layout and spatial awareness also continue in the Chinese character "square" structure cognition, the Chinese character structure itself with the meaning of the sacred square, it is often said that Chinese characters are "square character". This archetypal feature of Chinese characters extends to the political significance of Chinese characters, such as "Wang-San Hua Lian," which represents heaven, earth, and man; "Garden," for example, which seems to be the symmetry of the plane axis, the plane wall, and the trees and heaps of mountains and stones planted inside. In addition, the pond dug becomes a special artistic conception; for example, the "construction" structure used in traditional architecture has become the prototype of "collusion", and it has also been extended to the concept of interpersonal communication; and the Chinese character "state" structure also responds to the "heaven-human" echo. Is the artificial construction on the earth above the square sacred space. In the transition of the power of "country and country", the most direct mythological image continues. Just as Ye Shuxian, a cultural anthropologist, said: there are two basic image elements in the appearance of the Chinese character: as an offensive weapon, as a defensive building, inside a square outer wall barrier, and inside a smaller square inner city. These are the three detachable components of the Chinese character "Guo". The creators obviously wanted to leave the sturdy representation of the city in the pictographic symbols that represented the country. But the city alone is not enough to constitute a "country", between the outer city and the inner city, there is an important symbol of the armed elements, that is, enough to defend the city from foreign enemies attack weapons-GE (Ye 2014:3). This is the great tradiotional cultural information revealed by the word "country we are familiar with". Ancient people use jade to express the highest "Tiande”, "Shan Hai Jing” in the "overseas Western Sutra” its fourteen gods are pig body and Dai Yu. "the big mouth frame encloses" jade "and becomes" country "character, it is clear that people regard wearing jade as the same as the symbol of state power, which is the evolution of" theocracy "thinking to" rule by virtue "ethics.

In the previous generation of the great cultural tradition, the mythology "Kunlun covering the sky" expressed the consciousness of "the sky is like a vault, the cage covers four sides," and took the sky as the reference object. Looking for the "figurative theory" which surpasses the object image and the intuitionistic narration, embodies the "writing of all things in the body" in "making the image full of meaning", and then achieves the beauty of the anti-universe curve like Kunpeng's spreading wings in the architecture. Corresponding to the activities of the "ground", connecting the four geographical space and the formation of Guangyu Pangfang. Residence is also rules into "back" shape, no matter how deep the courtyard, are "eight directions" progressive, in order to reflect the residential "heaven and earth" and echo the "eight directions nine 
wild”. Both Chinese mythology and western religions regard respect for heaven as the common aspiration of the society. This is exactly what the Preface Gua of the Yi Chuan explains: "things cannot be poor, so there is no end to receiving them." it is an insatiable will activity that is never satisfied and seeks ceaselessly. Prehistoric people believe that there is a emperor in heaven, the "son of heaven" is to replace the emperor of heaven to the next management of the land and people, people in addition to the sky to believe in the emperor, but also to respect the emperor. The fate of heaven is not easy to maintain, the emperor should always amend the virtue, must perpetuate the way of heaven in order to offer sacrifices to reward the blessing. "Zuo Zhuan. Cheng Gong 13 years of the” cloud "state events, in worship and Rong”, "sacrifice and Rong” limited by the space and the legal tools are still in the ancestral temple, so the most visible symbol of power and control of force activities are still related to the building; According to the design requirement of "the right temple of the left ancestor", the city planning of the past dynasties echoed the central imperial city in the strict and symmetrical vertical and horizontal axis, and constituted the sacred direction of the building and the city wall in the psychology and the vision.

\section{IV.The Ethical Order in the Value Orientation of Aesthetic Thinking Under the Cultivation of the Character Struction}

Words, numbers and music are the three major symbol systems of human beings. The West emphasizes mathematics while China attaches great importance to words. "Chinese people put numbers and musical symbols in Chinese characters and make them subservient to Chinese characters. The Chinese express music with palace, Shang, Jiaoyu, Zheng, etc., express astronomical and mathematical relations with celestial stem and earthly branch, and endow abstract symbols with humanistic meaning” (Wang 2005:6), just because Chinese characters are metaphors of the most original cultural archetypes and civilization genes, writing is the spiritual wealth of the Chinese people and the medium for sharing the discourse of" the world view. "this thinking has lasted thousands of years of civilization.

After a long period of human intuition and symbolic stage, the intuitive world of thinking is not limited, all the mysteries of nature are in the interaction and imagination, what you see is what you know. But the symbol is close to the real state, some kind of meaning affects the spread of imaginative thinking, while the words are related to specify mophologies to form words and the multi-dimensional subjective cognition. To exert control over all things in the world, including the spiritual world, in a shared state. Just as Zhao Tingyang said: "to share this spiritual world is to share history, and to share this spiritual world shared by more people can gain greater political extension, and thus share the greater possible world that is most beneficial to existence” (Zhao 2005:23).

"Book of changes" husband adult, with the heaven and earth to combine its virtue, with the sun and the moon to combine its bright, with 04:00 in its order, with the ghosts and gods to combine its good or bad luck. "the order of human relations in China is related to" heaven and earth, the sun and the moon, 04:00, ghosts and gods". In the Book of songs, "in the prescription of the book of songs": "in the prescription of the book of songs, it was made in the Chu Palace.” At the beginning of the day, he made it in the Chu-shih. The hazelnut of the tree, chair Tongzi lacquer, hence felling piano mulberry. "the ancients fixed the stars in October in the southern sky corresponding to the North Star, the location of the best structure of wood to build the machine. Because at this time the autumn harvest is over, the cold winter has not yet arrived, the perfect leisure for farming has begun, and at the same time the "forefathers have planted trees," and in order to have good wood 
for sacrifice and for the future, they have planted the four trees of "hazelnut, chair and Tongzi lacquer." Everything seems to express a kind of respect of "a hundred years to cultivate people”, the metaphor of the material to take into account the human taste. The "logging" of the book of songs: "logging Ding, birdsong whining, out of the valley, moved to the Arbor.” The former artificial house at the same time planted trees in the backyard, waiting for wood when children grow up in the home, moving wood to build a new house, so back and forth, become China's human order.

Some scholars have pointed out that "the tradition of urban architecture in China is closely related to the farming civilization, and its mobility and the stillness of the local society constitute two wings of the social property” (Peng 2015:9). "Chinese settlement and farming life requires people to grow with crops, the so-called 'sky harvest'. Limited by the geographical climate, plant cultivation and harvest, four seasons and 24 seasons, there is a special "fallow time" in the relationship between farming metabolism. Chinese farmers develop various "lesheng" techniques in the fallow time. Agricultural leisure season is the flow and spread of various skills and customs, that is, the identity of farmers in the idle season changes for the neighboring craftsman. Not only enriched the economy, but also in the transmission of skills at the same time the spread of local ethics. Farming fosters cooperative, cooperative neighborhood relationships that allow for water conservancy, ploughing, grabbing, house-building, and repairs. This allows settlers to form groups, often in the form of ethnic groups, in which clansmen help each other. Bring up the "benevolence" of the farming style. However, the changes of contemporary economic survival law, local ethics are also reflected in the "transformation boom" in full swing, only to activate the deep myth gene of the universal identity, and back in contemporary society; May be able to rediscover the local customs and human relations.

Mr. Wang Renxiang pointed out: "the city, the writing, the metallurgy may take the civilization three essential factors, moreover the writing is most important”(Wang 1998:124). Therefore, searching for the mythological images of the big prehistoric traditions through the civilization of the Chinese characters since the small traditions have been recorded is the echo of the present Chinese spirit and the "treatment" of the lack of social ethical values.

The traditional Chinese architectural space, which is composed of rusticity and harmony, is the field for Chinese people to realize and pursue the ethical order, and it is the connotation of the public order and the good custom with a broad view of the cosmic space form. The traditional architecture interweaves the space thinking with the rational spirit and the romantic myth, turns the social creation "standard" and the esthetic realm which educates, is precisely the ethics Noumenon of the personality accomplishment and the humanities care. Retrospect the architectural space phenomenon in the ancient writing, reveal the myth phenomenon in the big cultural tradition and the background of its accompanying social behavior belief ethics, and use the inner logic of the ideographic expression in the text; Thus it is possible to unlock the architectural prototype gene in the historical changes covered with dust, access to the cultural power of the rejuvenation of a great nation.

\section{References}

Bruhl (1981). Primitive thinking. Beijing:The Commercial Press,92.

Butt·R (1999). Myth—Interpretation of Mass Culture. Shanghai:Shanghai People’s Publishing House,173.

Carl Gustav Jung, and Sun Mingli,etc (2011). Jung's Collection of Literature: Symbol of Conversion: An Analysis of the Precursors of Schizophrenia. Beijing: International Culture Press,18. 
Chen W. M.(2016) Pictures and Texts in Ancient Times and Mythological Prototypes_— Historical Data and Ideological Defects of Chinese Mythological Studies. Journal of Chongqing Universities of Arts and Sciences(Social Sciences and Society).35(1):71

Guo G. H. (2014). Reading History and Searching God: Codes in Mythology and Chinese Characters. Guilin:Guangxi Normal University Press,244.

Gu J. G. (2015) Speech of national history, ancient times. Shanghai:Shanghai People’s Publishing House,5.

Han Wei(2011) Scientific and Technological Information of Ancient Residential Buildings in Chinese Characters. Academic Journal of Zhongzhou,(1):241.

Li Y. H. (2014). Cathay Artistic Conception. Tianjin:Tianjin University Press,47.

Li Z. H. (2015). Outline of Philosophy. Latest Revised Edition. Beijing:Zhonghua Book Company,273.

Peng Z. R. (2016) City and Country: Urban Heritage with Chinese Characteristics. Journal of Beifang University of Nationalities, (1):55-59.

Peng Z.R., and Zhou X. F. (2015) The Urban Heritage of Native China. Journal of Beifang University of Nationalities,(5):7.

Philosophers integration(1954). One: The Analects of Confucius and Mencius. Beijing:Zhonghua Book Company,263.

Wang R. X. and Jia X. B. (1998). Prehistoric culture in China. Beijing:The Commercial Press,124.

Wang Sa, Zhang Y. K. , Zhang Nan(2014) Viewing the Implication of Chinese Traditional Space Planning Concept from Orientation Words —_Society—Orientation” Schema and Its Significance Analysis. The Architect,(1):75-83.

Wang W. Y. (2005). On the plurality of Chinese characters. Social Science Forum,(4):6.

Ye S. X. (2015) A Study of Jade's Mythology and Symbol Coding. Nation Arts, (2):22.

Ye S. X. (2014). Looking at the Origin of the Chinese Nation from the Prototype of the Chinese Character “國” — A Comment on "Chinese Cultural Exhibition in the Xia Dynasty: Jade Articles and Jade Culture”. Journal of Baise University, 27(3):3.

Zhao G. C. (2006). Not Only Chinese Wood Architecture. Beijing:SDX Joint Publishing Company,11.

Zhao T. Y. (2015). China as a political Theological concept. Jianghai Academic Journal,(5):23

Zhang Jun, Xu Li(2016) Implicit in Explicitness: Viewing the Design Thought of Character Creation from the Evolution of Chinese Character Modeling Language. Art of Design(Journal of Shandong University of Art and Design),(5):73.

Zhang W. J. (1994) Symbols·Chinese Characters and the Psychological Structure of the Han Nation. The Journal of Humanities , (1):107-113.

\section{Bio}

Chengxia Xiong, Ph.D., associate professor, Wuhan University of Technology, University of Shanghai for Science and Technology, Shanghai, China; research fields: cultural anthropology, architectural mythology.

Zejia Wang, University of Shanghai for Science and Technology, Shanghai, China; research fields: visual culture communication

Danyin Zhang, Ph.D., University of Shanghai for Science and Technology, Shanghai, China; research fields: architectural anthropology 